\title{
GENETIC DIVERSITY AND POPULATION STRUCTURE OF SIMILAR NAMED AROMATIC RICE (Oryza sativa L.) LANDRACES OF BANGLADESH
}

\author{
M.Z. Islam*, M. Khalequzzaman, T. Chakrabarty, N. Akter, M.F.R. Khan \\ A. Bhuiya, M.A. Siddique \\ Genetic Resources and Seed Division \\ Bangladesh Rice Research Institute, Gazipur, Bangladesh
}

\begin{abstract}
Assessment of thirty-six similar named aromatic rice landraces of Bangladesh was analyzed using 36 microsatellite markers to characterize the landraces and also to establish the sovereignty of the Bangladeshi rice gene pool. With an average of 3.03 per locus, overall 109 alleles differed from 2 to 5 were detected at 36 microsatellite loci across the 36 aromatic rice landraces. With an average of 0.48 , the diversity of genes ranged from 0.15 to 0.74 . The polymorphic information content (PIC) values ranged from 0.14 (RM500, RM554) to 0.69 (RM496), with an average of 0.41 , revealed many variations among the studied landraces. The recurrence of the most prevalent allele at each locus ranged from $31.00 \%$ (RM496) to $96.00 \%$ (RM500 and RM554). At any given locus, on average $64.33 \%$ landraces out of 36 contributed a familiar major allele. For identification and diversity estimation of aromatic rice landraces, RM496 was the finest marker as affirmed by PIC values. Two clusters were revealed with a similarity coefficient of 0.45 by a UPGMA dendrogram in SSR. All the landraces were also divided into two groups ( $A$ and $B$ ) through the model-based clustering method, confirmed by UPGMA cluster analysis. Some of the SSR markers (RM1, RM489, RM39, RM474, RM2, RM214, RM21, and RM206) generated unique alleles that were specific to particular landraces and were useful for varietal identification. Besides, the evaluation of genotypic data demonstrated the landraces under this study provided noticeable genetic diversity. Meanwhile, for the future breeding program, the similarly named landraces need to be safeguarded.
\end{abstract}

Keywords: Microsatellite markers, Cluster analysis, Polymorphic information content, Aromatic rice.

\footnotetext{
* Corresponding Author: zahid.grs@gmail.com
} 
Islam et al.

\section{INTRODUCTION}

One of the most popular food crops in the world is rice (Oryza sativa L.). In the case of special occasions and export purposes, aromatic rice is preferred over nonaromatic rice for its notable features. Also, due to its superior grain qualities and pleasant aroma aromatic rice is a notable class of rice with high market value (Singh et al., 2000). It's believed that the foothills of Himalayas, covering Bihar, Uttar Pradesh in India, and the Tarai region of Nepal are the center of diversity of aromatic rice landraces. After that, aromatic rice germplasm might be dispersed to the other different states within India and also neighboring countries like Bangladesh and excellently adapted to the local environments of those areas (Khush, 2000). At present, Bangladesh has more than 8000 rice germplasm of which more than 100 identified as aromatic landraces (Islam et al., 2016).

Aromatic rice landraces of Bangladesh generally have short and medium bold grain types with pleasurable aroma (Shahidullah et al., 2009). Usually, aromatic rice landraces contained tall-statured, the smaller number of panicles, high stem weight, lower yields, and are also susceptible to lodging and pests. Due to the presence of a non-functional betaine aldehyde dehydrogenase $2\left(\mathrm{BADH}_{2}\right)$ aromatic germplasm effuses fragrance which also responsible for low grain yield (Bradbury et al., 2005; Bradbury et al., 2008). Most of the aromatic rice landraces in Bangladesh are locally adapted, photoperiod-sensitive, and grown under rainfed lowland ecosystem during Transplanted Aman season (July to December). The average yield of high yielding rainfed lowland rice in Bangladesh is $3.4 \mathrm{t} \mathrm{ha}^{-1}$, whereas the average yield of aromatic rice is $2.0-2.3 \mathrm{tha}^{-1}$.

Currently, the valuable gene pool of aromatic rice landraces of Bangladesh is being eroded day by day because of the introduction of high yielding varieties (HYV) and their poor yield performance. Exploring diversity in the landrace collection is very essential for identifying new genes and further improvement of the germplasm (Thomson et al., 2007). However, similarly named rice germplasm was cultivated all over Bangladesh was identified (Hamid et al., 1982; Ahmed et al., 2016). Besides, different genotypes maybe got the same name given by many farmers or a particular genotype acquired several slightly deviated names. Hence, it is very important to study a similar named aromatic rice germplasm to identify whether they are the same or different. Some small and medium-grained of Bangladeshi aromatic rice landraces have the excellent aroma and few other quality traits like elongation after cooking, taste, etc. For measuring genetic diversity in crop germplasm and evaluating evolutionary relationships the commencement of PCR-based molecular marker technology provides highly effective and reliable tools (Islam et al., 2018a). Simple sequence repeat (SSR) markers can serve as the marker for selection and affords several advantages over other markers across various molecular markers (Roy et al., 
2016; Islam et al., 2019). Due to high reproducibility, simplicity, easy scoring ability, multi-allelic nature, hyper-variability, co-dominant inheritance, and genome-wide coverage SSR markers are highly suitable for characterizing rice germplasm (Powell et al., 1996). For genetic diversity analysis, characterization of genotypes, cultivar identification, marker-assisted selection breeding, and population structure assessment in several rice genetic studies, recently many researchers have been used SSR markers (Choudhury et al., 2013; Islam et al., 2018b). With the above background information, the present inquiry was undertaken by using SSR markers to assess the genetic variation in 36 similar named aromatic rice landraces of Bangladesh.

\section{MATERIALS AND METHODS}

\section{Plant materials and molecular marker}

We used 36 aromatic rice accessions representing landraces, farmer's varieties, and pure lines preserved in Bangladesh Rice Research Institute (BRRI) genebank as shown in Table1. These accessions were studied in the Molecular Laboratory of Genetic Resources and Seed Division of BRRI during 2016-17 for diversity analysis. A total of 42 pairs of primers were used from the previous studies on rice (McCouch et al., 2002; Islam et al., 2018a, 2018b); some were selected randomly. Detailed information of the primers is obtained from the websitewww.gramene.org/ markers/microsat.

\section{Molecular analysis using SSR marker}

Five grams seeds from each landrace were first germinated and then germinated seeds were sown in the earthen pots. The pots were kept in the net house for collecting $2 \mathrm{~g}$ fresh leaf samples for DNA extraction. DNA was isolated from young leaves of rice plants using the minor modified miniscale method (Islam et al., 2018a). Polymerase chain reaction (PCR) was carried out in a volume of $10 \mu \mathrm{L}$. Each reaction mixture contains $3.0 \mu \mathrm{L}$ genomic DNA, $1.0 \mu \mathrm{L}$ of $10 \mathrm{X}$ PCR buffer $\left(\mathrm{MgCl}_{2}\right.$ free), $1.35 \mu \mathrm{L}$ of $25 \mathrm{mmol} / \mathrm{L} \mathrm{MgCl}_{2}, 0.2 \mathrm{mM}$ of a dNTPs mix, $0.5 \mu \mathrm{L}$ of each forward and reverse primers, 1 unit of Taq DNA polymerase and $3.43 \mu \mathrm{L}$ sterile deionized water. PCR profile was set as follow: 1 cycle at $94^{\circ} \mathrm{C}$ for $5 \mathrm{~min}$ (initial denaturation), followed by 35 cycles of $94^{\circ} \mathrm{C}$ for $45 \mathrm{~s}$ (denaturation), annealing at $55^{\circ} \mathrm{C}$ for $45 \mathrm{~s}$ and extension at $72^{\circ} \mathrm{C}$ for $1.3 \mathrm{~min}$. Then additional temperature (final extension) of $72{ }^{\circ} \mathrm{C}$ for 7 minutes at the end of 35 cycles. The PCR products were subjected to electrophoresis in $0.5 \mathrm{X}$ TBE buffer for 1.5 to $2.50 \mathrm{~h}$. The gel was stained with ethidium bromide solution for $25 \mathrm{~min}$. Following this, the gel was viewed under UV light using a gel documentation system (XR System, Uvitec Cambridge, France). 
Table 1. Information on collection site, source and local name of the landraces

\begin{tabular}{|c|c|c|c|c|c|c|c|}
\hline Sl. No. & Landraces & Code Name & $\begin{array}{l}\text { Acc. } \\
\text { No. }\end{array}$ & Season & District & Origin & $\begin{array}{c}1.7 \% \mathrm{KOH} \\
(\text { aroma })\end{array}$ \\
\hline 1 & Chinigura & $\mathrm{C} 1$ & 6719 & T.Aman & Gazipur & Bangladesh & Scented \\
\hline 2 & Chinigura & $\mathrm{C} 2$ & 2412 & T.Aman & Dhaka & Bangladesh & Light scented \\
\hline 3 & Chinigura & $\mathrm{C} 3$ & 4867 & T.Aman & Mymensingh & Bangladesh & Light scented \\
\hline 4 & Chinigura & $\mathrm{C} 4$ & 7572 & T.Aman & Habiganj & Bangladesh & Scented \\
\hline 5 & Chiniguri & $\mathrm{C} 5$ & 1424 & T.Aman & Dhaka & Bangladesh & Scented \\
\hline 6 & Chiniguri & C6 & 1880 & T.Aman & Kishoreganj & Bangladesh & Scented \\
\hline 7 & Sakkorkhora & S1 & 1605 & T.Aman & Patuakhali & Bangladesh & Scented \\
\hline 8 & Sakkorkhana & S2 & 4761 & T.Aman & Barguna & Bangladesh & Scented \\
\hline 9 & Sakkorkhana & S3 & 5338 & T.Aman & Bagerhat & Bangladesh & Scented \\
\hline 10 & Sakkorkhana & S4 & 7316 & T.Aman & Jhalakati & Bangladesh & Light scented \\
\hline 11 & Sakkorkhana & S5 & 7500 & T.Aman & Pirojpur & Bangladesh & Light scented \\
\hline 12 & Sakkorkhora & S6 & 7506 & T.Aman & Pirojpur & Bangladesh & Scented \\
\hline 13 & Kataribhog & K1 & 232 & T.Aman & Mymensingh & Bangladesh & Light scented \\
\hline 14 & Kataribhog & $\mathrm{K} 2$ & 1091 & T.Aman & Jessore & Bangladesh & Scented \\
\hline 15 & Kataribhog & K3 & 1491 & T.Aman & Tangail & Bangladesh & Scented \\
\hline 16 & Kataribhog TAPL-78 & K4 & 2505 & T.Aman & Gazipur & Bangladesh & Scented \\
\hline 17 & Kataribhog TAPL-79 & K5 & 2506 & T.Aman & Gazipur & Bangladesh & Scented \\
\hline 18 & Kataribhog TAPL-80 & K6 & 2507 & T.Aman & Gazipur & Bangladesh & Scented \\
\hline 19 & Kataribhog TAPL-81 & K7 & 2508 & T.Aman & Gazipur & Bangladesh & Scented \\
\hline 20 & Kataribhog TAPL-82 & K8 & 2509 & T.Aman & Gazipur & Bangladesh & Scented \\
\hline 21 & Kataribhog TAPL-83 & K9 & 2510 & T.Aman & Gazipur & Bangladesh & Scented \\
\hline 22 & Kataribhog TAPL-84 & K10 & 2511 & T.Aman & Gazipur & Bangladesh & Scented \\
\hline 23 & Kataribhog TAPL-85 & K11 & 2512 & T.Aman & Gazipur & Bangladesh & Scented \\
\hline 24 & Kataribhog TAPL-86 & K12 & 2513 & T.Aman & Gazipur & Bangladesh & Light scented \\
\hline 25 & Kataribhog TAPL-87 & K13 & 2514 & T.Aman & Gazipur & Bangladesh & Light scented \\
\hline 26 & Kataribhog TAPL-88 & K14 & 2515 & T.Aman & Gazipur & Bangladesh & Scented \\
\hline 27 & Kataribhog & K15 & 4362 & T.Aman & Gazipur & Bangladesh & Scented \\
\hline 28 & Kataribhog & K16 & 4363 & T.Aman & Gazipur & Bangladesh & Scented \\
\hline 29 & Kataribhog & K17 & 4791 & T.Aman & Dinajpur & Bangladesh & Light scented \\
\hline 30 & Kataribhog & K18 & 7082 & T.Aman & Sylhet & Bangladesh & Light scented \\
\hline 31 & Begunbichi & B1 & 508 & T.Aman & Rangpur & Bangladesh & Light scented \\
\hline 32 & Begunbichi & B2 & 740 & T.Aman & Rangamati & Bangladesh & Light scented \\
\hline 33 & Begunbichi & B3 & 986 & T.Aman & Khulna & Bangladesh & Scented \\
\hline 34 & Begunbichi & B4 & 1465 & T.Aman & Dhaka & Bangladesh & Light scented \\
\hline 35 & Begunbichi & B5 & 1678 & T.Aman & Faridpur & Bangladesh & Scented \\
\hline 36 & Begunbichi & B6 & 4088 & T.Aman & Nilphamari & Bangladesh & Non-scented \\
\hline
\end{tabular}




\section{Data Analysis}

The molecular weight for each of the markers was measured using the AlphaEaseFC 4.0 software. The summary statistics include the number of alleles per locus, major allele frequency, and polymorphism information content (PIC) was obtained by the use of Power Marker V 3.25 (Liu and Muse, 2005). The allele frequency data from Power Marker software was calculated to export data and scored as 1 or 0 indicating the presence and absence of products of a particular size. NTSYS-pc software (Rohlf, 2002) was used for dendrogram construction.

The population structure of 36 aromatic landraces was determined using the STRUCTURE V2.3.4 software (Pritchard et al., 2000; Falush et al., 2003). The number of populations $(\mathrm{K})$ investigated here and ranged (1 - 10), replication: 5, burnin period length: 5000, run-length: 50000, and also a model allowing for admixture and correlated allele frequency. The output of the analysis was harvested using the 'Structure harvester' program (http://taylorO.biology.ucla.edu) and determined the final $\mathrm{K}$ value ( $\mathrm{K}=2$ was optimum for this analysis) based on both the $\mathrm{LnP}(\mathrm{D})$ and Evanno's $\Delta K$ (Evanno et al., 2005). In summary, the major patterns of variation in the multilocus dataset, an analysis of molecular variance (AMOVA) was performed using GenAlEx V 6.5 (Peakall and Smouse, 2012).

\section{RESULTS AND DISCUSSION}

For the efficient characterization, conservation, documentation and utilization of biodiversity, evaluation of genetic disparity in germplasm collections are obligatory. Genetic diversity in crop material is used as the basis for varietal improvement. The use of germplasm can be measured from the amount of available diversity in the material. The main objective is to know the possibility of classifying individual landraces into dissimilar groups from each genetic diversity study. Landraces which are studied in this context showed remarkable variations among the landraces for distinct agro-morphological traits (data not given). Molecular characterization, on the other hand, is the alternative approach to overcome several limitations of morphological characterization, which are high experimental cost, long evaluation time, and environmental effects. In past times characterization, genetic diversity and population structure of Bangladeshi rice germplasm have been studied by using molecular markers (Ahmed et al., 2016; Siddique et al., 2017; Islam et al., 2018a).

\section{Genetic diversity}

All the 36 aromatic rice landraces were genotyped with 42 simple sequence repeat (SSR) markers. Six markers (RM224, RM215, RM536, RM537, RM192, RM193) were found monomorphic (data are not shown), exhibiting one allele at each locus for all the landraces among 42 SSR markers. Then again, based on polymorphism 36 SSR markers were selected to use for molecular characterization of the aromatic rice landraces. 
A total of 109 alleles were identified at 36 SSR markers over 36 aromatic landraces (Table 2). RM496 (262 bp) produced the maximum amplicon size and RM413 (66 bp) was the minimum. In the case of RM489 (242-315 bp), a maximum range of band sizes was found and succeeded by RM496 (262-314 bp) and RM474 (227-292 bp), respectively. The number of alleles per locus ranged from 2 alleles (RM178, RM507, RM510, RM447, RM282, RM487, RM554, RM542, RM500, RM560, RM342, RM553 and RM20) to 5 alleles (RM474), with an average of 3.03 alleles across the 36 loci. The PIC values differed from 0.14 (RM500, RM554) to 0.69 (RM496), with the 0.41 average. SSRs which have higher PIC values have a higher number of alleles. Lower PIC value shows that the landraces under study are closely allied, whereas the higher value of PIC stipulates the higher array of materials which is the utmost need for the new variety development. RM496 primer had the highest PIC (0.69) value and the number of alleles (5) were highest. It detected the maximum level of polymorphism. Therefore, RM496 marker confirmed that it was the best marker for characterizing the studied landraces. The most common allele was ranged from $31.00 \%$ (RM496) to $96.00 \%$ (RM500, RM554) at each locus. On average, $64.33 \%$ of the 36 rice landraces shared a common major allele at any given locus. The DNA figuration of 36 aromatic rice landraces by RM447 is demonstrated(Fig. $1)$.

From the present study, the genetic diversity is similar to earlier report (Islam et al., 2018a); where investigators identified 3.11 alleles per locus and an average PIC value of 0.29 among 113 aromatic rice germplasm. Correspondingly, 88 Indian rice varieties were collected from different agro-climatic regions of India having 3 alleles per locus with a mean PIC value of 0.41, also reported by Yadav et al. (2013). Again, the average PIC value of 0.44 was observed by Chakhonkaen et al. (2012) among 43 Thai and 57 IRRI germplasm of rice. Further, Ahmed et al. (2016) found 350 alleles from similarly named rice germplasm using 45 SSR markers and several alleles per locus ranged from 3 to 14 with an average of 7.8 which was higher than the present study. On the other hand, a marginally lower genetic diversity was disclosed among 40 rice accessions of Pakistan with an average of 2.75 alleles per locus and an average PIC value of 0.38 (Shah et al., 2013).

Again, a lower SSR diversity was found in a study with thirty-six (36) polymorphic HvSSRs where they identified 2.22 alleles per locus and mean PIC value of 0.25 in 375 Indian rice genotypes gathered from totally different areas of India (Singh et al., 2013). In this study, the PIC values projected that RM496 might be the leading marker for diversity analysis of aromatic rice germplasm, followed by RM214, RM474 and RM567 were probably the least potent markers $(>0.60)$. So, these microsatellite markers may be useful tools for the upcoming genetic studies of rice germplasm. 
Table 2. Allele number, allele size and frequency, gene diversity and polymorphism information content (PIC) found among 36 similar named aromatic rice landraces for 36 microsatellite markers

\begin{tabular}{|c|c|c|c|c|c|c|c|c|c|c|}
\hline Markers & $\begin{array}{l}\text { Chromoso } \\
\text { me No. }\end{array}$ & $\begin{array}{l}\text { Position } \\
\text { (cM) }\end{array}$ & Motif* & $\begin{array}{l}\text { Allele } \\
\text { No. }\end{array}$ & $\begin{array}{c}\text { No. of } \\
\text { Unique } \\
\text { allele }\end{array}$ & $\begin{array}{c}\text { Size } \\
\text { range } \\
\text { (bp) }\end{array}$ & $\begin{array}{l}\text { Size } \\
\text { (bp) }\end{array}$ & $\begin{array}{l}\text { Freq } \\
(\%)\end{array}$ & $\begin{array}{c}\text { Gene } \\
\text { diversity }\end{array}$ & PIC \\
\hline RM1 & 1 & 29.7 & (GA)26 & 5 & 1 & $82-122$ & 122 & 64.00 & 0.55 & 0.51 \\
\hline RM489 & 3 & 29.2 & $(\mathrm{ATA}) 8$ & 4 & 2 & $242-315$ & 242 & 78.00 & 0.37 & 0.33 \\
\hline RM39 & 5 & 87.7 & (CT) $17 \mathrm{CCA}(\mathrm{TC}) 3$ & 3 & 1 & $102-118$ & 118 & 69.00 & 0.44 & 0.36 \\
\hline RM178 & 5 & 118.8 & $(\mathrm{GA}) 5(\mathrm{AG}) 8$ & 2 & 0 & $116-121$ & 121 & 86.00 & 0.24 & 0.21 \\
\hline RM507 & 5 & - & $(\mathrm{AAGA}) 7$ & 2 & 0 & $242-250$ & 250 & 83.00 & 0.28 & 0.24 \\
\hline RM510 & 6 & 20.8 & (GA)15 & 2 & 0 & $112-120$ & 120 & 89.00 & 0.20 & 0.18 \\
\hline RM223 & 8 & 80.5 & (CT) 25 & 4 & 0 & $153-168$ & 168 & 56.00 & 0.61 & 0.56 \\
\hline RM447 & 8 & 124.6 & $(\mathrm{CTT}) 8$ & 2 & 0 & $105-112$ & 112 & 67.00 & 0.44 & 0.35 \\
\hline RM105 & 9 & 32.1 & $(\mathrm{CCT}) 6$ & 3 & 0 & $128-140$ & 140 & 53.00 & 0.61 & 0.54 \\
\hline RM316 & 9 & 1.8 & $\begin{array}{c}(\mathrm{GT}) 8- \\
\text { (TG)9(TTTG)4(TG)4 }\end{array}$ & 4 & 0 & $184-205$ & 184 & 50.00 & 0.65 & 0.59 \\
\hline RM474 & 10 & - & (AT) 13 & 5 & 1 & $227-292$ & 227 & 47.00 & 0.68 & 0.64 \\
\hline RM552 & 11 & 40.6 & (TAT) 13 & 3 & 0 & $172-224$ & 172 & 53.00 & 0.54 & 0.45 \\
\hline RM262 & 2 & 103.3 & (CT) 16 & 3 & 0 & $149-165$ & 149 & 69.00 & 0.47 & 0.43 \\
\hline RM16 & 3 & 131.5 & (TCG)5(GA)16 & 3 & 0 & $186-237$ & 186 & 72.00 & 0.43 & 0.37 \\
\hline RM282 & 3 & 100.6 & (GA)15 & 2 & 0 & $138-145$ & 136 & 75.00 & 0.38 & 0.30 \\
\hline RM487 & 3 & 127.9 & (AC) 10 & 2 & 0 & $175-181$ & 175 & 78.00 & 0.35 & 0.29 \\
\hline RM554 & 3 & 100.6 & (GA)14 & 2 & 0 & $250-257$ & 257 & 92.00 & 0.15 & 0.14 \\
\hline RM518 & 4 & 25.5 & (TC) 15 & 3 & 0 & 154-169 & 169 & 75.00 & 0.40 & 0.35 \\
\hline RM567 & 4 & 153.6 & $(\mathrm{GA}) 21$ & 4 & 0 & $240-266$ & 261 & 36.00 & 0.69 & 0.63 \\
\hline RM334 & 5 & 141.8 & (CTT)20 & 3 & 0 & 178-191 & 178 & 64.00 & 0.50 & 0.42 \\
\hline RM413 & 5 & 26.7 & (AG) 11 & 4 & 0 & $66-106$ & 66 & 64.00 & 0.54 & 0.51 \\
\hline RM190 & 6 & 7.4 & (CT)11 & 3 & 0 & $115-135$ & 135 & 56.00 & 0.57 & 0.51 \\
\hline RM2 & 7 & 36.1 & $(\mathrm{GA}) 13$ & 3 & 1 & $140-155$ & 155 & 78.00 & 0.36 & 0.31 \\
\hline RM214 & 7 & 34.7 & (CT) 14 & 5 & 1 & $120-142$ & 120 & 36.00 & 0.73 & 0.68 \\
\hline RM542 & 7 & 34.7 & (CT) 22 & 2 & 0 & $95-138$ & 138 & 58.00 & 0.49 & 0.37 \\
\hline RM320 & 7 & 62.5 & (AT) $11 \mathrm{GTAT}(\mathrm{GT}) 13$ & 3 & 0 & $135-170$ & 170 & 67.00 & 0.49 & 0.42 \\
\hline RM500 & 7 & 36.1 & $(\mathrm{AAG}) 9$ & 2 & 0 & $240-252$ & 252 & 92.00 & 0.15 & 0.14 \\
\hline RM560 & 7 & 54.2 & (CT) 12 & 2 & 0 & $228-235$ & 235 & 56.00 & 0.49 & 0.37 \\
\hline RM72 & 8 & 60.9 & (TAT)5C(ATT) 15 & 3 & 0 & $180-198$ & 180 & 61.00 & 0.51 & 0.43 \\
\hline RM342 & 8 & 78.4 & $(\mathrm{CAT}) 12$ & 2 & 0 & $134-157$ & 141 & 75.00 & 0.38 & 0.30 \\
\hline RM553 & 9 & 76.7 & (CT) 10 & 2 & 0 & $174-184$ & 172 & 61.00 & 0.48 & 0.36 \\
\hline RM496 & 10 & 113 & (TC) 14 & 4 & 0 & $262-314$ & 262 & 31.00 & 0.74 & 0.69 \\
\hline RM21 & 11 & 85.7 & $(\mathrm{GA}) 18$ & 4 & 1 & $135-160$ & 160 & 53.00 & 0.62 & 0.55 \\
\hline RM206 & 11 & 102.9 & (CT) 21 & 4 & 1 & $134-172$ & 172 & 61.00 & 0.54 & 0.48 \\
\hline
\end{tabular}




\begin{tabular}{|c|c|c|c|c|c|c|c|c|c|c|}
\hline Markers & $\begin{array}{c}\text { Chromoso } \\
\text { me No. }\end{array}$ & $\begin{array}{c}\text { Position } \\
\text { (cM) }\end{array}$ & Motif* & $\begin{array}{c}\text { Allele } \\
\text { No. }\end{array}$ & $\begin{array}{c}\text { No. of } \\
\text { Unique } \\
\text { allele }\end{array}$ & $\begin{array}{c}\text { Size } \\
\text { range } \\
\text { (bp) }\end{array}$ & $\begin{array}{l}\text { Size } \\
\text { (bp) }\end{array}$ & $\begin{array}{l}\text { Freq } \\
(\%)\end{array}$ & $\begin{array}{c}\text { Gene } \\
\text { diversity }\end{array}$ & PIC \\
\hline RM224 & 11 & 120.1 & $(\mathrm{AAG}) 8(\mathrm{AG}) 13$ & 3 & 0 & $136-156$ & 156 & 53.00 & 0.54 & 0.47 \\
\hline RM20 & 12 & - & $(\mathrm{ATT}) 14$ & 2 & 0 & $220-235$ & 235 & 58.00 & 0.49 & 0.37 \\
\hline Total & & & & 109 & 9 & & 6236 & 2316 & 17.1 & 14.85 \\
\hline Min & & & & 2 & & & 66 & 31 & 0.15 & 0.14 \\
\hline Mean & & & & 3.03 & & & $\begin{array}{c}173 . \\
22\end{array}$ & 64.33 & 0.48 & 0.41 \\
\hline $\operatorname{Max}$ & & & & 5 & & & 262 & 92 & 0.74 & 0.69 \\
\hline
\end{tabular}

Unique alleles are valuable as they may be effectively indicative of particular landraces and also for a breeding purpose. Additionally, eight markers magnified nine unique alleles among 36 markers. Here, the RM1 magnified the 122 bp allele which was distinct to the Begunbichi landrace (B5). Again, the RM489 intensified the particular alleles of 248 and 315 bp in the landraces namely Chiniguri (C6) and Kataribhog (K1), respectively. The prominent aromatic rice landraces "Chinigura (C2)" was exclusively identified by RM39, "Kataribhog (K3)" by RM474 and "Kataribhog (K18)" by RM2. Normally, the higher number of unique alleles in germplasm indicates as a reservoir of novel alleles. Some unique alleles per locus varied from 1 to 2 (Table 2). The application of of unique alleles for molecular characterization of crop has been reported earlier (Das et al., 2013; Islam et al., 2018a). Among Basmati and non-Basmati rice varieties, Saini et al. (2004) noticed 58 unique alleles $(36.2 \%)$.

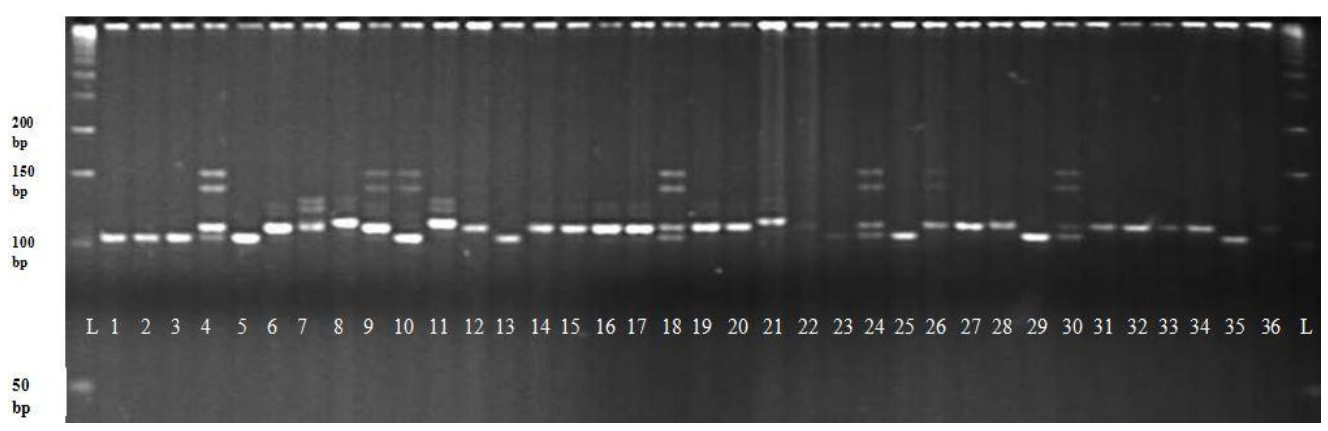

Figure 1. Gel picture of marker RM447 showing banding pattern in 36 aromatic rice landraces $(\mathrm{L}=\mathrm{DNA}$ Laddaer $50 \mathrm{bp}$ )

\section{Genetic distance-based analysis}

The genetic distance-based results in the UPGMA cluster analysis revealed two major clusters in the 36 genotypes at a coefficient of 0.45 in SSR and the similarity coefficient value ranged from 0.33 to 0.97 in SSR which is an indication of the 
genetic variation among the accessions based on the SSR primers (Fig. 2). Cluster I consisted of 11 aromatic landraces $(\mathrm{C} 1, \mathrm{C} 2, \mathrm{C} 3, \mathrm{C} 5, \mathrm{~S} 4, \mathrm{~B} 5, \mathrm{~K} 1, \mathrm{~K} 11, \mathrm{~K} 12$, K13 and K17). Again, cluster I was further divided into 2 sub-clusters (A and B). Sub-cluster A, incorporated popular landraces viz, Chinigura group (C1, C2, C3 and C5), S4 and B5. Sakkorkhana (S4) and Begunbichi (B5) are popular T. Aman landraces from Jhalakati and Faridpur districts of Bangladesh. Sub cluster-B consisted of Kataribhog group (K1, K11, K12, K13 and K17) from Mymensingh, Gazipur and Dinajpur district. Again, cluster II was further divided into 2 subclusters (A and B). Sub cluster-A, included 24 local popular aromatic landraces and sub-cluster-B consisted of one landrace namely Kataribhog (K18) from Sylhet. Kataribhog group (K4 and K5) aromatic landraces have high similarity and close placed in phylogenetic tree analyses. In previous study, Islam et al. (2018a) found three (3) major clusters and few sub-clusters through the UPGMA cluster analysis among 113 aromatic rice landraces.

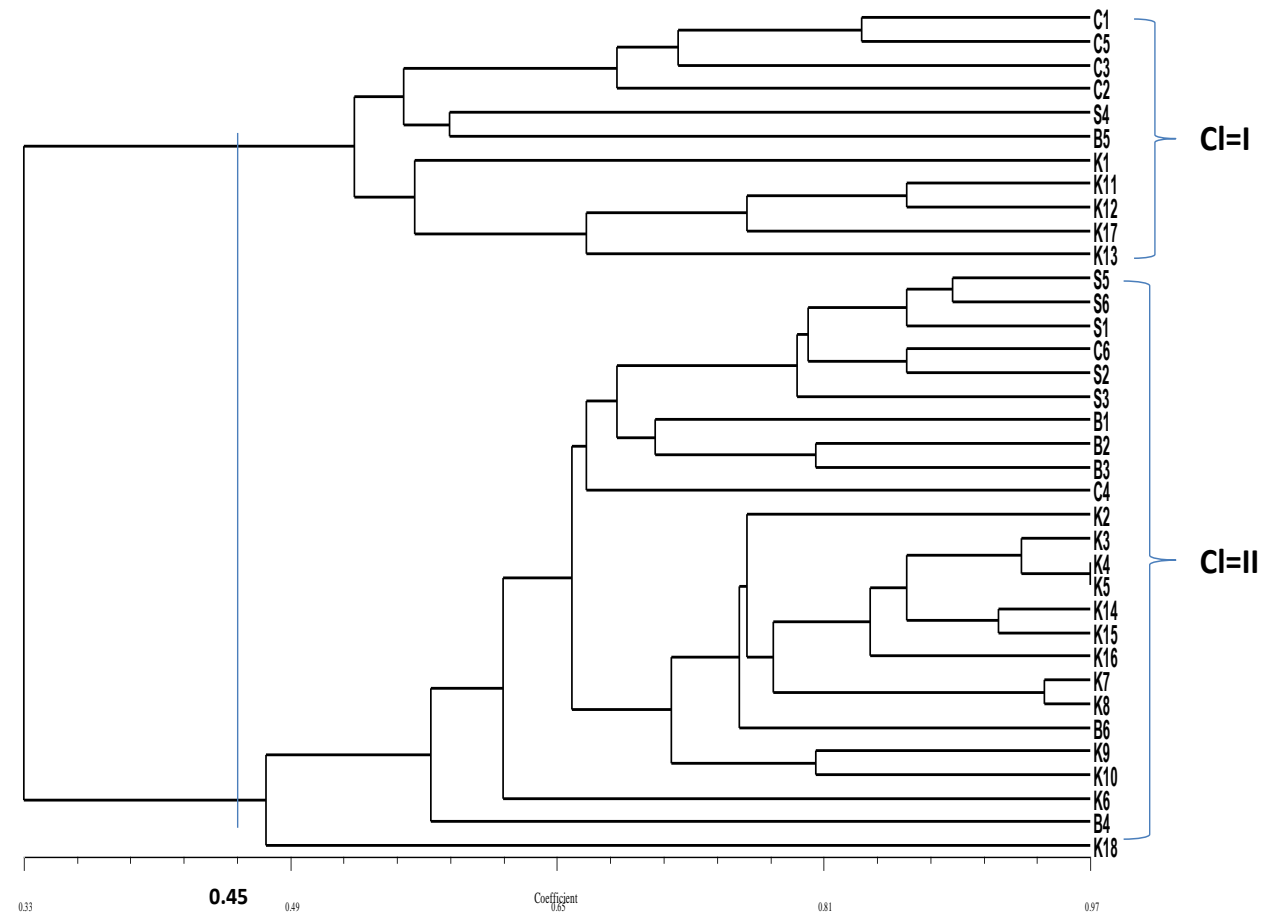

Figure 2. An UPGMA cluster dendrogram showing the genetic relationships between 36 aromatic rice landraces of Bangladesh based on the alleles detected by 36 microsatellite markers. 


\section{Model-based population structure}

The population structure analysis declared the log-likelihood value $(\Delta \mathrm{K})$ maximized to the highest value of at $\mathrm{K}=2$ (Fig. 3), demonstrating a sharp peak expressing the classification of entire landraces into two specific sub-groups, here denoted as Group A and Group B, respectively.

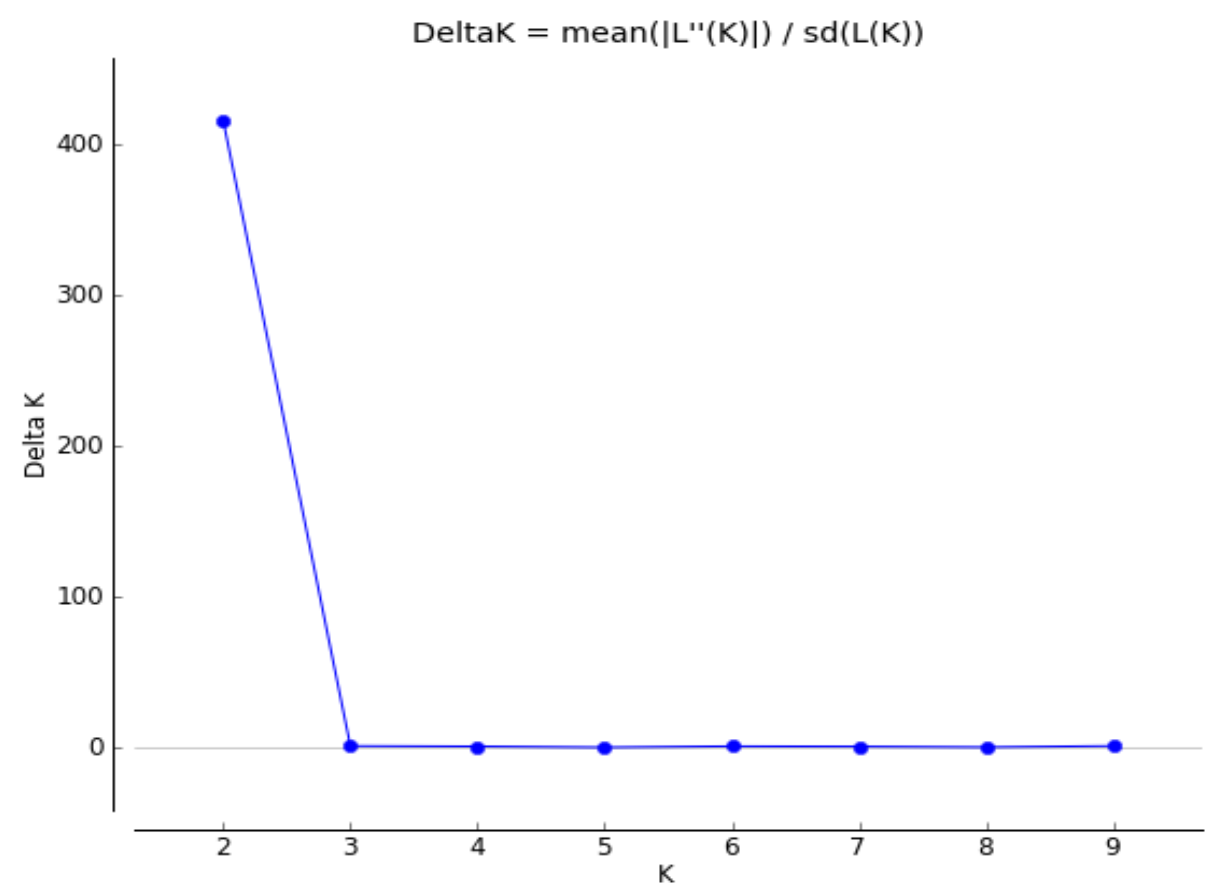

Figure 3. Representation of population structure dividing the landraces in two subgroups based on $\mathrm{K}$ value.

To find out the number of pure and admixed individuals, populations were studied. The population Group A (red colour, Fig. 4) and Group B (green colour, Fig. 4) representing $27.78 \%$ (10) and $72.22 \%$ (26) of aromatic landraces used in structure analysis, respectively. Overall, 05 (13.89\%) admixed landraces were found at $\mathrm{K}=2$. It may be noted that Group A had 12 aromatic accessions with 10 pure and 2 admixed landraces and Group B had 24 aromatic accessions with 21 pure and 3 admixed landraces. The population grouping through structural analysis and distancebased clustering demonstrated a similar result.

The Bayesian clustering approach implements to choose the number of groups with peak log-likelihood (Lu et al., 2005). From different rice diversity panels, population structure analysis has marked different numbers of sub-groups, ranged from 2 to 8 (Garris et al., 2005; Das et al., 2013; Islam et al., 2018b). With the help of structure 
analysis, the 36 aromatic accessions of this study were investigated into two important groups and disclosed an adequately consistent genetic liaison with the dendrogram.

From this study, QTLs/genes mapping can be constructed by using the diverse landraces and highly polymorphic SSR markers that have been determined for different physicochemical quality traits. Finally, it can be wrapped up that similarly named aromatic rice landraces need to be preserved in genebank.

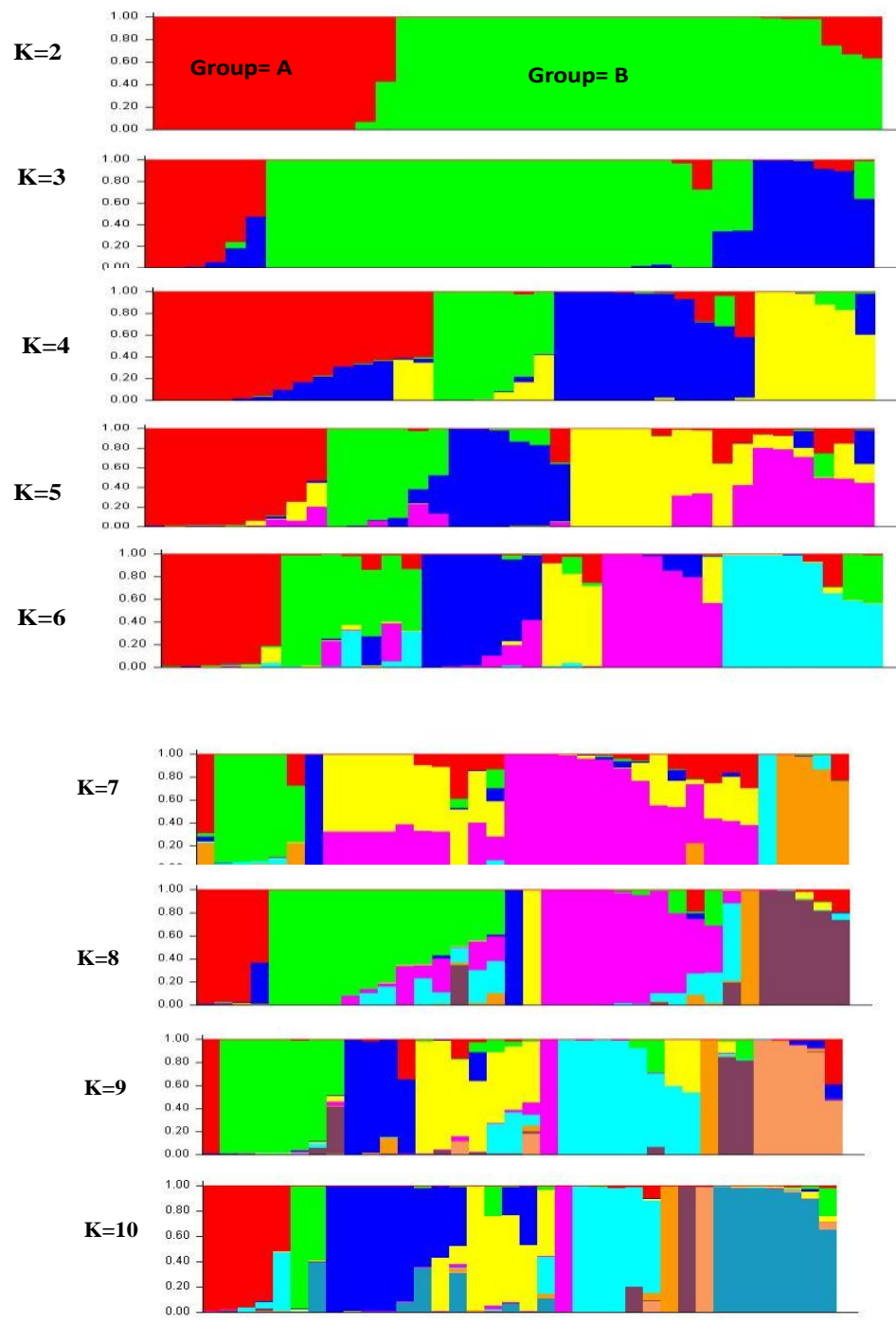

Figure 4. Population structure at $\mathrm{K}=2$ to $\mathrm{K}=10$ of 36 aromatic rice landraces based on genotypic data using 36 microsatellite markers. 


\section{Analysis of molecular variance (AMOVA) from the model-based approach}

From the structural analysis, two populations were consequently demonstrating to AMOVA to determine the fluctuation across and within populations. In the time, $11 \%$ variance was recorded across populations for individuals, $87 \%$ variance among, and $1 \%$ within were found (Fig. 5, Table 3). Mostly, by using the phylogenetic treebased similarity coefficient distribution as well as the structure analysis, results from the AMOVA complied with findings achieved.

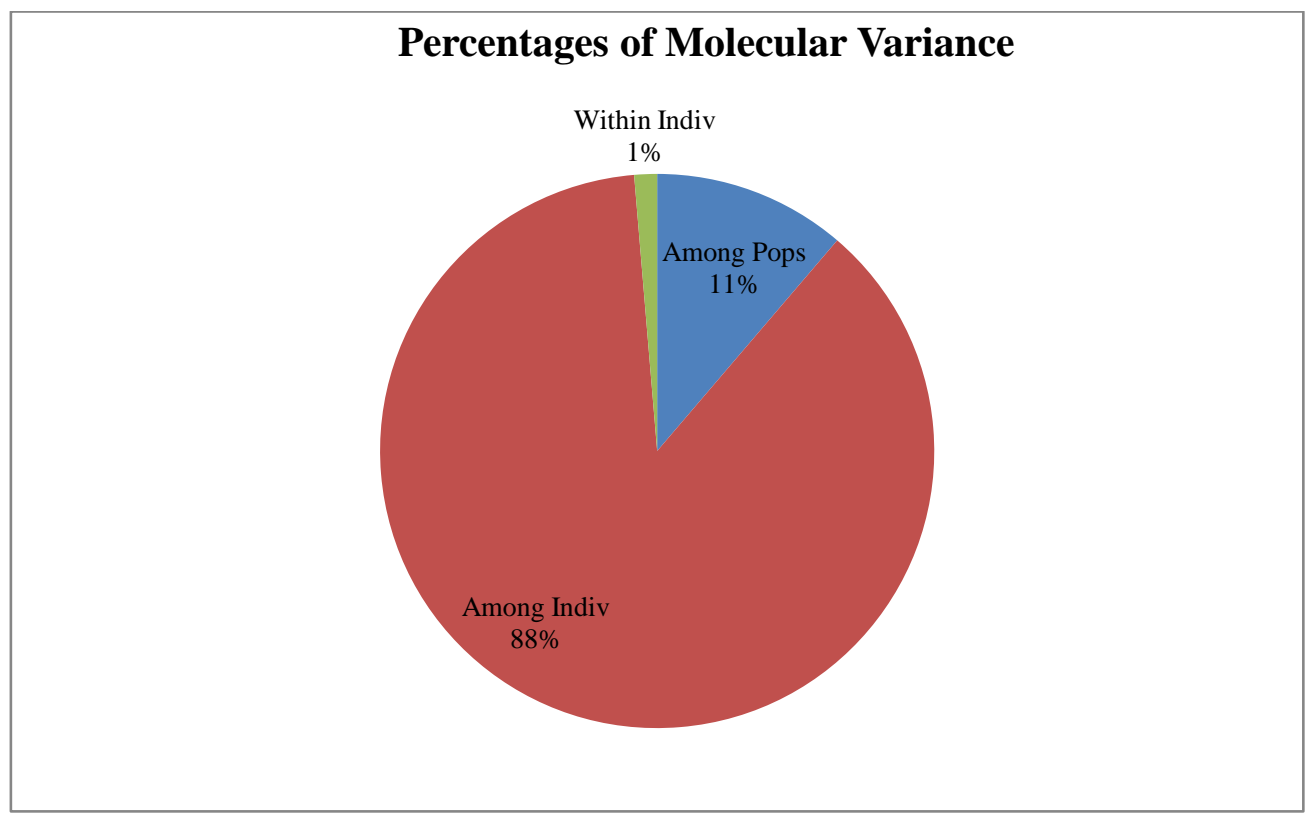

Figure 5. Analysis of molecular variance (AMOVA) of 36 aromatic rice landraces using 36 SSR markers.

Table 3. Analysis of molecular variance (AMOVA) of aromatic landraces available in Bangladesh

\begin{tabular}{lccccc}
\hline Source & $\begin{array}{c}\text { Degree } \\
\text { freedom }\end{array}$ & $\begin{array}{c}\text { Sum } \\
\text { Square }\end{array}$ & $\begin{array}{c}\text { Mean } \\
\text { Square }\end{array}$ & $\begin{array}{c}\text { Estimated } \\
\text { Variance }\end{array}$ & \% Variance \\
\hline Among Population & 1 & 50.521 & 50.521 & 1.060 & $11 \%$ \\
Among Individual & 34 & 564.104 & 16.591 & 8.233 & $87 \%$ \\
Within Individual & 36 & 4.500 & 0.125 & 0.125 & $1 \%$ \\
Total & 71 & 619.125 & & 9.418 & $100 \%$ \\
\hline
\end{tabular}




\section{CONCLUSION}

An enormous genetic variability at molecular level revealed in this study. Analysis of population structure from the SSR markers grouped all the landraces into 2 groups according to geographical district or origin. Besides, 2 groups were also constructed using SSR markers data clustering analysis. Hence, the most divergent landraces obtained in this study can be utilized for the future aromatic rice breeding programme. Also, from this study, the diverse landraces and highly polymorphic SSR markers which have been identified can be used for QTLs/genes mapping for different physicochemical quality traits. Finally, it can be concluded that similarly named aromatic rice landraces need to be preserved in Genebank as they contain profuse genetic variation and can exploit tremendously in future breeding program.

\section{ACKNOWLEDGMENT}

The authors are grateful for the financial support provided by the Bangladesh Rice Research Institute (BRRI) through the Ministry of Agriculture, Bangladesh.

\section{CONFLICT OF INTEREST}

There is no conflict of interest.

\section{REFERENCES}

Ahmed, M.S.U., Khalequzzaman, M., Bashar, M.K. and Shamsuddin, A.K.M. (2016). Agromorphological, physico-chemical and molecular characterization of rice germplasm with similar names of Bangladesh. Rice Science, 23(4): 211-218.

Bradbury, L.M.T., Gillies, S.A., Brushett, D.J., Waters, D.L.E. and Henry, R.J. (2008). Inactivation of an aminoaldehyde dehydrogenase is responsible for fragrance in rice. Plant Molecular Biology, 68: 439-449.

Bradbury, L.M.T., Fitzgerald, T.L., Henry, R.J., Jin, Q. and Waters, D.L.E. (2005). The gene for fragrance in rice. Plant Biotechnology Journal, 3: 363-370.

Chakhonkaen, S., Pitnjam, K., Saisuk, W., Ukoskit, K. and Muangprom, A. (2012). Genetic structure of Thai rice and rice accessions obtained from the International Rice Research Institute. Rice, 5: 19.

Choudhury, B., Khan, M.L. and Dayanandan, S. (2013). Genetic structure and diversity of indigenous rice varieties (Oryza sativa) in Eastern Himalayan region of Northeast India. Springer Plus, 2: 228-237.

Das, B., Sengupta, S., Parida, S.K., Roy, B., Ghosh, M., Prasad, M. and Ghose, T.K. (2013). Genetic diversity and population structure of rice landraces from Eastern and North Eastern States of India. BMC Genetics, 14: 71.

Evanno, G., Regnaut, S. and Goudet, J. (2005). Detecting the number of clusters of individuals using the software STRUCTURE: a simulation study. Molecular Ecology, 14: $2611-2620$. 
Falush, D., Stephens, M. and Pritchard, J.K. (2003). Inference of population structure using multilocus genotype data: linked loci and correlated allele frequencies. Genetics, 164: 1567-1587.

Garris, A.J., Tai, T.H., Coburn, J., Kresovich, S. and McCouch, S. (2005). Genetic structure and diversity in Oryza sativa L. Genetics, 169:1631-1638.

Hamid, A., Uddin, N., Haque, M. and Haque, E. (1982). Deshi Dhaner Jat (Bangla). Publication no.59. Bangladesh Rice Research Institute, Gazipur, Bangladesh.

Islam, M.Z., Khalequzzaman, M., Bashar, M.K., Ivy, N.A., Mian, M.A.K., Pittendrigh, B.R., Haque, M.M. and Ali, M.P. (2018a). Variability assessment of aromatic rice germplasm by pheno-genomic traits and population structure analysis. Scientific Reports, 8: 9911.

Islam, M.Z., Khalequzzaman, M., Prince, M.F.R.K., Siddique, M.A., Rashid, E.S.M.H., Ahmed, M.S.U., Pittendrigh, B.R. and Ali, M.P. (2018b). Diversity and population structure of red rice germplasm in Bangladesh. PLoS ONE, 13(5): e0196096.

Islam, M.Z., Khalequzzaman, M., Bashar, M.K., Ivy, N.A., Haque, M.M. and Mian, M.A.K. (2016). Variability assessment of aromatic and fine rice germplasm in Bangladesh based on quantitative traits. The Scientific World Journal, 2016, Article ID 2796720.

Islam, M.Z., Siddique, M.A., Akter, N., Prince, M.F.R.K., Islam, M.R., Anisuzzaman, M. and Mian, M.A.K. (2019). Morpho-molecular divergence of restorer lines for hybrid rice (Oryza sativa L.) development. Cereal Research Communication, 47(3): 531-540.

Khush, G.S. (2000). Taxonomy and Origin of Rice. In: Singh, R.K., U.S. Singh and G.S. Khush (Ed.), Aromatic rice. Oxford and IBH, New Delhi. Pp. 5-13.

Liu, K. and Muse, S.V. (2005). Power Marker: an integrated analysis environment for genetic marker analysis. Bioinformatics, 21(9): 2128-9.

Lu, H., Redus, M.A., Coburn, J.R., Rutger, J.N. and McCouch, S.R. (2005). Population structure and breeding patterns of 145 U.S. rice cultivars based on SSR marker analysis. Crop Science, 45: 66-76.

McCouch, S.R., Teytelman, L., Xu, Y., Lobos, K.B., Clare, K., Walton, M., Fu, B., Maghirang, R., Li, Z., Xing, Y., Zhang, Q., Kono, I., Yano, M., Fjellstrom, R., DeClerk, G., Schneider, D., Cartinhour, S., Wari, D. and Stein, L. (2002). Development and mapping of 2240 new SSR markers for rice (Oryza sativa L.). DNA Research, 9: 199-207.

Peakall, R. and Smouse, P.E. (2012). GenAlEx 6.5: genetic analysis in excel. Population genetic software for teaching and research-an update. Bioinformatics, 28: 2537-2539.

Powell, W., Machray, G.C. and Provan, J. (1996). Polymorphism revealed by simple sequence repeats. Trends in Plant Science, 1: 215-222.

Pritchard, J.K., Stephens, M. and Donnelly, P. (2000). Inference of population structure using multilocus genotype data. Genetics.155: 945-959.

Rohlf, F.J. (2002). NTSYS-pc. Numerical taxonomy and multivariance analysis system version 2.1. New York, USA: Exeter Software. 
Roy, S., Marndi, B.C., Mawkhlieng, B., Banerjee, A., Yadav, R.M., Misra, A.K. and Bansal, A.K. (2016). Genetic diversity and structure in hill rice (Oryza sativa L.) landraces collected from the North-Eastern Himalayas of India. BMC Genetics, 17: 107.

Saini, N., Jain, N., Jain, S. and Jain, R.K. (2004). Assessment of genetic diversity within and among Basmati and non-Basmati rice varieties using AFLP, ISSR and SSR markers. Euphytica.140: 133-146.

Shah, S.M., Naveed, S.A. and Arif, M. (2013). Genetic diversity in basmati and non-basmati rice varieties based on microsatellite markers. Pakistan Journal of Botany, 45: 423431.

Shahidullah, S.M., Hanafi, M.M., Ashrafuzzaman, M., Ismail, M.R. and Khair, A. (2009). Genetic diversity in grain quality and nutrition of aromatic rices. African Journal of Biotechnology, 8(7): 1238-1246.

Siddique, M.A., Khalequzzaman, M., Fatema, K., Islam, M.Z., Baktiar, M.H.K.and Islam, M.M. (2017). DNA fingerprinting and genetic diversity in Aus rice (Oryza sativa L.) landraces of Bangladesh. Bangladesh Rice Journal, 21(1): 59-65.

Singh, N., Choudhury, D.R., Singh, A.K., Kumar, S., Srinivasan, K., Tyagi, R.K., Singh, N.K. and Singh, R. (2013). Comparison of SSR and SNP markers in estimation of genetic diversity and population structure of Indian rice varieties. PLoS One. 8(12): e84136.

Singh, R.K., Gautam, P.L., Saxena, S. and Singh, S. (2000). Scented rice germplasm: conservation, evaluation and utilization. p. 107-133. In: R.K. Singh, U.S. Singh and G.S. Khush (ed.). Aromatic rices. Oxford \& IBH Publication, New Delhi.

Thomson, M.J., Septiningsih, E.M., Suwardjo, F., Santoso, T.J., Silitonga, T.S. and McCouch, S.R. (2007). Genetic diversity analysis of traditional and improved Indonesian rice (Oryza sativa L.) 481 germplasm using microsatellite markers. Theory of Applied Genetics, 114(3): 559-568.

Yadav, S., Singh, A., Singh, M.R., Goel, N., Vinod, K.K., Mohapatra, T. and Singh, A.K. (2013). Assessment of genetic diversity in Indian rice germplasm (Oryza sativa L.): use of random versus trait-linked microsatellite markers. Journal of Genetics, 92: 3.

Zheng, K. (1995). Rapid DNA isolation for marker assisted selection in rice breeding. Rice Genetics Newsletter, 12: 255-8. 